\title{
OS DESAFIOS DA EDUCAÇÃO AMBIENTAL NO SETOR AGROPECUÁRIO DIANTE DA MUDANÇA DO CLIMA
}

\author{
Thais Antolini Veçozzi ${ }^{1}$ \\ Marco Antônio Simões de Sousa ${ }^{2}$
}

Resumo: A agropecuária desempenha um duplo papel no contexto da mudança do clima, pois emite gases de efeito estufa, enquanto o solo utilizado pode funcionar como um sequestrador de carbono. Assim, o presente estudo buscou entender como a Educação Ambiental nesse setor pode ajudar a enfrentar a mudança do clima. Percebeu-se que é por meio da Educação Ambiental que se espera gerar mudança de pensamento e de ações daqueles que trabalham e administram a terra. No entanto, a realidade de pequenos $e$ grandes produtores difere, sendo importante que as ações alternativas para reduzir as emissões de gases de efeito estufa foquem no que é importante para os produtores, mesmo que para alguns o aspecto econômico tenha mais valor.

Palavras-chave: Educação Ambiental; Agropecuária; Mudança do Clima.

Abstract: Agriculture plays a dual role in the context of climate change, as it emits greenhouse gases, while the soil used can act as a carbon scavenger. Thus, the present study sought to understand how environmental education in this sector can help to face climate change. It was realized that it is through Environmental Education that it is expected to generate a change in the thinking and actions of those who work and manage the land. However, the reality of small and large producers differs, so it is important that alternative actions to reduce greenhouse gas emissions focus on what is important for producers, even if for some the economic aspect has more value.

Keywords: Environmental Education; Agriculture; Climate Change.

2 Instituto Federal Sul Riograndense - campus Pelotas. E-mail: marco@pelotas.ifsul.edu.br 


\section{Introdução: por que incentivar a Educação Ambiental no setor agropecuário?}

O Painel Intergovernamental sobre a Mudança do Clima (IPCC Intergovernmental Panel on Climate Change), organização que reúne e sintetiza os principais estudos científicos sobre a mudança do clima, suas causas e consequências, apontou no seu último relatório que a emissão de gases de efeito estufa (GEE) advindos das atividades antrópicas é a principal responsável pela mudança do clima (IPCC, 2014). Dentre essas atividades estão, principalmente, a queima de combustíveis fósseis para geração de energia e o grupo de atividades ligadas à agricultura, silvicultura e outros usos da terra, sobretudo devido ao desmatamento e degradação do solo.

No entanto, embora as atividades agropecuárias atualmente contribuam com uma grande parcela das emissões de GEE, o solo agrícola possui alto potencial para mitigar essas emissões. Ao se optar por realizar um manejo conservacionista do solo, ou seja, que evite perdas dos nutrientes, o solo remove carbono $(\mathrm{C})$ da atmosfera, realizando o processo inverso à emissão. Assim, a agropecuária realiza um duplo papel no contexto da mudança do clima, podendo ser uma das causas ou uma das soluções para a mudança do clima dependendo de como os agricultores exercem essa atividade.

Estando ciente da severidade das possíveis consequências da mudança do clima, estão vinculados à educação os principais instrumentos a serem empregados para que o futuro não se concretize em um dos piores cenários projetados, caso a taxa de emissão de GEE permaneça ou aumente de magnitude. Ações e acordos governamentais são básicos para alcançar metas para um planeta mais sustentável, mas somente são efetivos quando conseguem atingir uma mudança social. É neste campo que a Educação Ambiental (EA) tem alcançado seus objetivos, através do processo que inclui: acesso à informação de qualidade, percepção da realidade individual e coletiva, reflexão e transformação do estilo de vida.

Agricultura e pecuária sustentável, controle dos fatores que afetam a mudança do clima e educação são temas abordados entre as metas estabelecidas pela Assembleia Geral das Nações Unidas nos "Objetivos de Desenvolvimento Sustentável2" (UNITED NATIONS, 2018). Assim, é por meio de ações pautadas em princípios da EA que podemos planejar um caminho

\footnotetext{
2 O conceito mais aceito de desenvolvimento sustentável é "o desenvolvimento capaz de suprir as necessidades da geração atual, sem comprometer a capacidade de atender as necessidades das futuras gerações". No entanto, embora a ONU utilize este termo, ele difere de sustentabilidade, mais utilizado na Educação Ambiental já que "a sustentabilidade é um conceito normativo sobre a maneira como os seres humanos devem agir em relação à natureza, e como eles são responsáveis para com o outro e as futuras gerações" (SARTORI; LATRÔNICO; CAMPOS, 2014, p. 4). Segundo Matta (2013), o desenvolvimento sustentável está relacionado mais ao sistema econômico, não fortalecendo a preocupação com as pessoas e o meio ambiente.
} 
concreto para enfrentar um dos maiores desafios que temos atualmente, considerando que a mudança do clima está atrelada a problemas ambientais, sociais, econômicos, tanto regionais quanto globais.

Além das dificuldades presentes em qualquer processo educativo, nesse âmbito ainda se encontram alguns empecilhos atribuídos à mudança de comportamento de uma população com pensamentos fortemente enraizados que levam grande parte da comunidade de agricultores e pecuaristas a ter um posicionamento contrário a questões ambientas (GODOY; WIZNIEWSKY; FERREIRA, 2013). Assim, um dos grandes desafios é o de conscientizar sobre a mudança do clima pessoas que trabalham no campo ou estudam em áreas e que as prioridades muitas vezes divergem daquelas defendidas pelas ciências ambientais, sendo o setor agropecuário e o das ciências agrárias exemplos disso. As perspectivas futuras para o clima exigem que sejam tomadas todas as medidas plausíveis o mais breve possível visando à adoção de novas escolhas no estilo de vida, sendo-nos obrigados a considerar as mais diferentes alternativas para buscar enfrentar esse problema como seres humanos que vivem em sociedade no planeta Terra (TAMAIO, 2013).

Assim, diante da forma como as atividades agropecuárias são conduzidas no país, esse setor é, sem dúvida, um dos principais responsáveis pela emissão de GEE para a atmosfera. No entanto, com base nos estudos que pesquisadores que defendem que as atividades agropecuárias devem estar associadas a preservação ambiental, esta é uma das áreas que possuem o maior potencial para contribuir para a redução das emissões. Além disso, como defende Tamaio (2013), sendo a ação humana a causa mais preocupante do problema, somente através da educação que gere ação e participação pode-se esperar mudanças positivas para enfrentarmos a mudança do clima. Assim, entendemos que é fundamental informação, mobilização e Educação Ambiental em escala global e regional.

Neste contexto, percebendo a importância da EA para ajudar a resolver esses problemas, torna-se necessário também entender como e através de quais instrumentos a EA atua, quais são os meios por ela permeados e quais são os desafios que enfrenta ao colocar temas e ideais outrora controversos como mudança do clima e agropecuária lado a lado na busca por uma sociedade sustentável e um meio ambiente sadio.

Diante do exposto, o presente estudo tem como objetivo entender como a EA no setor agropecuário poderia ajudar a enfrentar a mudança do clima. A fim de abranger essa temática, o trabalho buscou identificar qual é a contribuição da agropecuária para a mudança do clima e qual a relevância da EA nesse contexto, sugerir como a EA pode ser abordada no setor agropecuário, pesquisar as principais políticas existentes e, assim, apontar os desafios centrais da educação para a mudança do clima no setor agropecuário. 


\section{Condução da pesquisa}

A condução das discussões apresentadas no presente estudos foi baseada em uma pesquisa bibliográfica nas plataformas digitais Scielo, Web of Science, Google Scholar utilizando termos como "mudança climática e agropecuária", "Educação Ambiental", "Educação Ambiental popular", "educação no campo", "educação e mudança climática", procurando referências teóricas publicadas com o objetivo de recolher informações ou conhecimentos prévios sobre a problemática a respeito da qual se procura a resposta (FONSECA, 2002, P. 32). Além disso, foram explorados os portais oficias de revistas científicas que tradicionalmente possuem publicação referente ao tema, como os periódicos "Revista Brasileira de Educação Ambiental", "Revista Eletrônica do Mestrado de Educação Ambiental" e "Pesquisa em Educação Ambiental".

Como forma de atender um dos objetivos propostos, foi realizado um levantamento da base legal sobre "Educação Ambiental" e "Educação Ambiental no âmbito da mudança do clima e da agropecuária". Após, realizouse uma pesquisa exploratória das principais políticas e planos aplicáveis em âmbito nacional que aplicam o disposto na legislação.

Com o entendimento do diagnóstico da base científica sobre a contribuição da agropecuária para a mudança do clima e da base legal e das políticas públicas existentes, discorreu-se criticamente sobre os desafios que a Educação Ambiental enfrenta enquanto Educação Ambiental Popular. Acrescentando, apontamos alguns esclarecimentos sobre o duelo meio ambiente $x$ economia e como são tomadas as decisões de agricultores $e$ pecuaristas sobre opções de produção mais sustentáveis.

\section{Entendendo as relações entre Educação Ambiental, mudança do clima e agropecuária}

\section{Mudança do clima e a participação da Educação Ambiental}

A elevação da concentração de GEE na atmosfera advinda das emissões antrópicas é considerada a principal causa da mudança do clima, visto que os GEE afetam direta e indiretamente o balanço radioativo da Terra (IPCC, 2014). Dentre as atividades humanas que emitem GEE para a atmosfera, a produção de alimentos pelas atividades agropecuárias desempenha duplo papel no contexto da mudança do clima, pois ao mesmo tempo em que é um dos maiores responsáveis pela emissão de GEE, a agropecuária possui alto potencial de mitigar as emissões de GEE devido a sua capacidade de sequestrar C da atmosfera para o solo. No Brasil, mais de $70 \%$ da emissão desses gases advém da agropecuária e das atividades ligadas à mudança no uso do solo (SEEG, 2017). Este cenário torna visíveis as atividades que mais emitem GEE e, consequentemente, onde os esforços para mitigar as emissões trariam resultados mais significativos. Assim, esse tipo de

revista brasileira educação ambiental 
conhecimento nos permite inferir que no Brasil, as principais oportunidades para mitigar as emissões desses gases estão associadas às atividades agropecuárias.

Com o objetivo de evitar e/ou amenizar as possíveis consequências da mudança do clima da Terra, como o aumento de temperatura e da ocorrência e intensidade de eventos extremos, a busca pela redução da emissão de GEE oriundos das atividades antrópicas é um dos principais focos da atualidade. Os esforços têm sido realizados através da realização de estudos para desenvolver novas tecnologias e também pela adoção das tecnologias que já são conhecidas como sendo mais limpas e conservacionistas, que emitem GEE em menores quantidades quando comparadas aos sistemas convencionais, mas que são ao mesmo tempo capazes de manter a eficiência na produção de alimentos visto que esse setor é essencial para o abastecimento da população. É em função disso que têm se buscado soluções e alternativas para reduzir as emissões de GEE sem comprometer o objetivo da atividade na produção de alimentos.

A ligação entre mudança do clima, emissão de GEE e agropecuária fica ainda mais clara quando se percebe que os cultivos agrícolas e a criação de animais, e consequentemente os agricultores e pecuaristas, por serem altamente dependentes do clima serão um dos principais afetados negativamente pelas consequências da mudança do clima. Como resultado dessas alterações poderá ser observado perdas significativas nas safras de grãos e alteração na geografia da produção agrícola brasileira, colocando em risco a segurança alimentar no país.

Como destaca Azevedo et al. (2017), o meio ambiente sofre em função da errônea interpretação de que desenvolvimento significa somente avanço tecnológico e industrialização, em uma competição desenfreada e consumista. O foco não deve ser no desenvolvimento econômico a qualquer custo, com a deterioração dos bens naturais e das sociedades. No entanto, ao tratarmos de uma atividade onde os envolvidos estão tão fortemente atrelados ao objetivo relacionado à maior produção e renda, deparamo-nos com a dificuldade de reconhecimento da mudança do clima como uma causa nobre e um problema que deve ser encarado pela comunidade em geral por ser algo que afetará a todos. Assim como defendem Pellegrino, Assad e Marin (2007), a economia de um país deve estar vinculada a um desenvolvimento equilibrado e sustentável, pois não há mais espaço para pensamentos e ações que concebam os bens naturais de maneira ilimitada. Para tanto, tratando-se de um país com base econômica agropecuária como o Brasil, é preciso conhecer o papel que a agricultura, pecuária e o uso do solo de maneira geral exercem atualmente e rever se desejamos que essas atividades sejam vilãs ou parte da solução.

Tem-se presenciado significativos avanços quanto à importância da preocupação com a mudança do clima e preservação ambiental. De forma geral, os caminhos mais eficazes que permitem e asseguram conscientização 
ambiental são dependentes do acesso à educação de qualidade, formação humana, envolvendo sensibilização e visando à mudança de hábitos. No entanto, observa-se que grande parte da população reconhece que questões ambientais como a mudança do clima são importantes, mas tais questões são deixadas de lado quando assuntos emergentes pessoais econômicos entram em jogo.

Diante desse contraste "economia vs. meio ambiente", o desafio para o enfrentamento das causas e das consequências da mudança do clima torna-se imensamente complexo. Nesse âmbito, a EA "em tempos de mudança do clima deve estar centrada nas mudanças e transformações humanas, propondo alternativas para o modelo e a cultura materialistas que colocam em risco a humanidade" (TAMAIO, p. 54, 2013). É assim, com pensamento de grande abrangência e com foco em ações específicas que a EA precisa ser vista como o principal e mais sólido caminho para enfrentarmos a mudança do clima.

Esta busca por uma sociedade mais sustentável pode ser baseada no que defende o autor Edgar Morin (apud PLASTINO, 2006), ao destacar que o humanismo "não poderá mais ser portador da orgulhosa vontade de dominar o universo, [passando] a ser essencialmente o da solidariedade entre humanos, o qual implica uma relação umbilical com a natureza e com o cosmos". De acordo com Saheb e Rodrigues (2017), a EA e o pensamento da complexidade de Morin se misturam e se complementam por possuírem ideias congruentes para a superação da crise paradigmática, principalmente no que tange ao campo educacional, reafirmando a ideia de que é preciso repensar a estrutura do ensino em todas as áreas.

De acordo com Reigota (2009, p. 10), a EA também precisa ser vista do ponto de vista político "no sentido de que ela reivindica e prepara os cidadãos para exigir justiça social, cidadania nacional e planetária, autogestão e ética nas relações sociais e com a natureza". De acordo com esse autor, a EA deve voltar-se para a comunidade, para que ela possa definir quais são os objetivos, os problemas e as alternativas, mas sem se esquecer de que dificilmente essa comunidade vive isolada. Ela está no mundo, recebendo influências diversas e também influenciando outras comunidades, num fluxo contínuo e recíproco. Assim, a EA entra nesse contexto para auxiliar e incentivar o cidadão a participar da resolução dos problemas e da busca por alternativas no cotidiano de realidades específicas. Os problemas ambientais foram criados por homens e mulheres e somente deles poderão vir as soluções. No entanto, embora seja necessário ciência e ações políticas, as esperanças não são colocadas em gênios, políticos ou tecnocratas, mas sim em todo e cada um dos cidadãos.

Entre os anos de 2008 e 2009, a International Alliance of Leading Education Institutes (IALEI) realizou uma pesquisa global sobre "Mudança do Clima e Desenvolvimento Sustentável: a resposta da educação", contando com a participação de dez países, incluindo o Brasil (IALEI, 2009). O resultado da pesquisa gerou um relatório onde foram estabelecidas questões centrais, 
sendo três sobre educação para o desenvolvimento sustentável de maneira holística, havendo uma em especial que procurava abordar a educação diante das alterações do clima, sendo citada conforme o seguinte questionamento: "Pode a educação contribuir com o desafio de lidarmos com a necessidade de mitigação e adaptação à mudança do clima? Se sim, como se daria tal contribuição e como esta influenciaria a educação para o desenvolvimento sustentável e vice-versa?' (idem, p. 7).

Segundo a IALEI, no que tange à educação, a mudança do clima consiste em uma problemática singular para se avaliar a real "capacidade de se organizar a aprendizagem em torno de problemas caracterizados por dinâmicas sociais complexas, conhecimento incerto e riscos" (IALEI, p.14, 2009). De maneira global, os relatórios de países desenvolvidos mostram que somente nos últimos anos o tema educação para a mudança do clima (climate change education) começou a ter um espaço próprio, o que demonstra o quão inicial esta questão ainda se encontra.

Segundo o relatório citado anteriormente, no Brasil, podemos observar um modelo descentralizado, havendo o compartilhamento da responsabilidade para conseguir uma maior abrangência através de ações tomadas por organizações não-governamentais, níveis de governo mais regionalizados como estados e prefeituras e iniciativas privadas. No entanto, independente da distribuição das incumbências, a educação sobre a mudança do clima, por ser um tema que trata de uma questão global, ainda merece ser abordada privilegiadamente tanto na educação formal como na não formal, de maneira a incluir toda a sociedade. Assim, todos poderiam ter acesso à informação e ser capazes de refletir sobre suas atividades e como elas estão impactando o ambiente. Por outro lado, a EA sobre a mudança do clima também possibilita a compreensão e reconhecimento dos direitos e deveres que devem ser assegurados e cumpridos por cada um de nós.

Conhecendo nossa realidade, têm-se consciência de que a EA por si só não resolverá os complexos problemas ambientais planetários. No entanto, como salientado por Reigota (2009, p.18-19) ela pode

influir decisivamente para isso, quando forma cidadãos e cidadãs conscientes dos seus direitos e deveres. Tendo consciência e conhecimento da problemática global e atuando na sua comunidade e vice-versa haverá uma mudança na vida cotidiana que, e não é de resultados imediatos, visíveis, também não sem efeitos concretos.

Neste cenário, fazendo-se uma fusão de dois direitos fundamentais, educação e meio ambiente ecologicamente equilibrado (BRASIL, 1988), surge 
a EA com fundamento na preocupação social, frente à qualidade de vida da presente geração e da existência das futuras gerações.

Segundo afirma Jacobi et al. (2011, p. 146)

de uma perspectiva pedagógica e metodológica, há uma necessidade urgente de encontrar alternativas de aprendizagem para abordar um tema cujos cenários são negativos e problemáticos, como indicam os relatórios do IPCC, sem cair num ponto de vista catastrofista de imobilismo ou, em contrapartida, numa visão simplista a respeito de uma questão tão importante e crucial à sociedade contemporânea.

Essa abordagem crítica remete-nos ao conceito de cidadania ambiental, a qual envolve reflexões e ações de efetiva participação e de mobilização, com outras pessoas, na busca de soluções e/ou na prevenção de possíveis riscos ambientais a partir de "comportamentos ecologicamente desequilibrados" (SATO, 2003). Assim, vislumbram-se na EA ferramentas estratégicas para sensibilizar os indivíduos na direção de uma consciência ecológica e evitar um futuro que pode ser trágico tanto para o meio ambiente geobiofísico quanto para uma parcela muito grande da população.

\section{Educação Ambiental no contexto agropecuário}

Um dos fatos principais que marcaram o início da EA está diretamente ligado à agropecuária. O lançamento do livro Silent Spring, de Rachel Carson, em 1962, mostrou um questionamento acerca do modelo de produção convencional e dependente do petróleo, do uso indiscriminado de substâncias tóxicas e a consequente perda da qualidade de vida produzida pelo uso excessivo dos produtos químicos e os efeitos dessa utilização sobre a natureza. A grande contribuição deste livro está em dar destaque a problemas ambientais ao despertar a sociedade para a necessidade da preocupação com a deterioração dos recursos naturais, o que já era objeto de muitos outros trabalhos que, desde 0 século XIX inspiravam políticas públicas conservacionistas adotadas pelos Estados Unidos.

No Brasil, a EA tornou-se "um componente essencial e permanente da educação nacional, devendo estar presente, de forma articulada, em todos os níveis e modalidades do processo educativo, em caráter formal e não formal" (BRASIL, 1999). Princípios de EA normalmente são abordados em disciplinas de gestão ou legislação ambiental em faculdades de engenharia agronômica e agrícola, medicina veterinária e zootecnia para profissionais e/ou futuros profissionais do campo. Além disso, cursos que de alguma forma passam informações sobre legislação ambiental são comumente organizados por

revista brasileira educação ambiental 
sindicatos, consultores e prefeituras. Por outro lado, no cenário agropecuário, o entendimento dos critérios que classificam uma atividade como educação ou a excluem deste universo parece não ser ainda plenamente compartilhado ou suficientemente explicitado em função da ampla informalidade que há no meio rural. No contexto ambiental-rural, segundo Carvalho (2005), as atividades que genericamente poderiam ser classificadas como de EA, como ações de intervenção para melhoria e manejo do meio ambiente, não estão necessariamente vinculadas a uma intenção educativa direta, e, portanto, não têm a EA como sua razão de ser, ou nem mesmo incluem esta dimensão entre outras em sua implementação, mas ainda assim são equivalentes e legítimas à EA.

$\mathrm{Na}$ ampla pesquisa realizada por Carvalho (2005), em quatro das cinco regiões do Brasil, a autora destaca que as ações de EA estão muito mais ligadas e apoiadas por projetos do que programas, predominando itens de curto e médio prazo sobre ações de longo prazo. Considerando que os programas são atreladas à ações em sua maioria afeitas à políticas públicas, pelas características de ações de longo prazo e maior enraizamento na estrutura institucional, isso conduz ao pensamento de que mesmo entre as instituições governamentais vigora a modalidade de projetos mais do que a de programas, o que aponta para a realidade da precarização das políticas públicas e da realização de ações isoladas uma das outras.

Essa valorização do rápido, do prático, é decorrente da atual conjuntura sócio-histórica do Brasil. Seguindo o pensamento de Carvalho (2005), estamos em uma época onde a sociedade possui acesso à informação, estando mais fortalecida em sua capacidade de ação e organização, mas politicamente vê-se fragilizada pelos processos de globalização financeira que enfraquecem o local, o regional, o tradicional, reduzindo a consolidação de políticas públicas contínuas e duradouras. Assim, vemo-nos ainda sob efeito da Revolução Verde (RV), que forçou um processo de modernização do campo a partir de modelos importados de outros países, que acelerou a degradação ambiental e levou a um processo de exclusão social do homem do campo em valia dos grandes proprietários de terra (BARROS; LIHTNOV, 2016). O processo de RV na agricultura é apontado como o principal transformador das práticas agrícolas e pecuárias, consequentemente visto como o fator responsável pela degradação ambiental e social no meio rural.

Embora ainda seja necessário encarar essa realidade não favorável aos produtores familiares, que são ainda mais produtivos do que os grandes produtores rurais, sendo responsáveis pela produção de mais de $50 \%$ dos alimentos da cesta básica brasileira (SECRETARIA DE AGRICULTURA FAMILIAR E COOPERATIVISMO, 2019), é possível esperar a geração de um comportamento social e cultural em que se verifica a assimilação de um ideário de valores ambientais tanto através de avanços tecnológicos e científicos quanto da valorização do conhecimento tradicional que essas comunidades possuem. Exemplos desse cenário podem ser observados com o crescente 
interesse pela produção agroecológica, pela agricultura conservacionista, pelo uso de práticas de baixo impacto ao solo e às águas. Embora não explicitamente, essas práticas estão muitas vezes associadas a ações de EA, tanto na sua efetivação como na valorização da paisagem socioambiental no campo e das comunidades tradicionais.

No entanto, como sugere Carvalho (2001), acredita-se que o conceito de "comportamento" não seria suficiente para tratar da complexidade do agir humano. Segundo a autora, a abrangência de problemas globais como a mudança do clima não exigiria apenas a indução de novos comportamentos, pois isso pode ser dar de maneira seletiva e pontual, sem refletir em uma transformação de fato, no sentido da construção de um novo ethos, de um novo pacto civilizatório desejado por um ideário ecológico emancipatório. Nesse sentido, mesmo com a mudança de comportamento, alguém seria capaz de aprender a valorizar um ambiente saudável e conservado, através de ações como não sujar as ruas e participar dos mutirões de limpeza do seu bairro, e ao mesmo tempo poder considerar adequada a política de produção e transferência de lixo para outra região e não se importar com a poluição de um lugar distante do seu ambiente de vida.

Comumente são notados esses tipos de mudanças, simplistas e pontuais, que claramente não exigem grandes esforços ou renúncia de nenhum conforto. Nessa perspectiva individualista, a preservação do meio ambiente além de ser imediata é pontual, pois precisa-se considerar o prejuízo que isso possa ter, por exemplo, para outras populações afetadas por estes resíduos. Neste sentido, seria possível um comportamento preocupado com o meio ambiente local, para uso de uma população particular e seletiva, sem que seja necessário um envolvimento ou compromisso com comunidades distantes ou uma preocupação com o planeta como um todo.

Nessa linha de pensamento de Carvalho (2001), a EA possui a capacidade para promover valores ambientais que ultrapassam a mera aquisição de informação, baseando-se firmemente na aprendizagem ativa, considerada como a construção de novos sentidos e nexos para a vida. Essa mudança real é um processo que abrange transformações no indivíduo que permitem que seu aprendizado reflita na sua identidade e posturas diante do mundo. $O$ despertar para a preocupação com problemas globais, envolvidos por todas as comunidades e não só as próprias, também atravessa 0 convencimento de um sobre outro sobre os problemas ambientais mundiais (que ainda são sociais e econômicos), traçando um caminho que leva à criação de um vínculo com valores éticos, comunitários e estéticos desta visão de mundo que possui o sujeito ecológico.

Partindo desse entendimento, percebe-se que uma EA que visa apenas a mudança comportamental é considerada suficiente para ações específicas, localizadas, com objetivos bem definidos, mas dificilmente é capaz de incorporar um ambiente com problemas mais amplos, como a grave mudança 
do clima. A EA popular ${ }^{3}$, por outro lado, é composta por uma diversidade de instrumentos que entrelaçados possuem a habilidade de agir de maneira mais eficaz na formação de sujeitos. Assim, seriam os instrumentos da EA popular os mais indicados para realizarem mediações educativas no ambiente rural, para tratar de assuntos da esfera ambiental pública, incluindo nesta o debate que interliga práticas agrícolas, conservação dos recursos ambientais às problemáticas da emissão de gases de efeito estufa e da mudança do clima.

Segundo destaca Carlos (2016), nas ações de EA no meio rural é indispensável investigar a percepção de produtores e como ela se relaciona às suas características socioeconômicas. Como defende a autora, esse conhecimento poderá fornecer subsídios para que se possam desenvolver estratégias de ação que permitam promover mudanças frente às dificuldades locais, pois a compreensão da interpretação ambiental dos agricultores é um fator crucial para a adoção e eficácia dos mecanismos de adaptação.

Para que os produtores optem pela adoção de medidas adaptativas frente às alterações do clima é fundamental, primeiramente, que os produtores percebam que o clima está mudando e a partir disso, que é necessária a identificação de possíveis medidas adaptativas para, então, efetivar a sua implementação (MADDISON, 2007). Considera-se que o planejamento de ações de adaptação climática requer, necessariamente, a análise das alternativas de decisão, levando em conta as possibilidades e limitações de cada técnica, assim como as incertezas associadas à mudança do clima (PIDGEON; FISCHHOFF, 2011).

Na perspectiva da EA popular, o papel do educador é o de mediar a comunidade para o entendimento sobre as relações que agricultor estabelece com a terra e na busca por reflexões sobre as consequências que suas decisões possuem para as demais comunidades e para o planeta. Assim, o educador na EA popular também age como um organizar e intérprete do conhecimento que os produtores rurais previamente possuem, exercendo a função de facilitador das ações individuais e dos grupos, o que possibilita a geração da aprendizagem que realmente é capaz de alterar os indivíduos.

No entanto, sabendo-se da variação e da quantidade de conhecimento que as comunidades de agricultores e pecuaristas possuem, acredita-se que para discutir assuntos que envolvem processos químicos e físicos associados às ciências exatas, como a emissão de gases de efeito estufa pela agropecuária e a mudança do clima, seria necessária a apresentação de informações científicas em uma linguagem adaptada para cada nível de escolaridade das comunidades. Diante da infinita geração de informações e do

${ }^{3}$ A Educação Ambiental popular se coloca entre as camadas populares por meio de debates sobre o acesso aos recursos, à injusta distribuição das consequências ambientais, resultados das ações depredadoras e exploradoras, expandindo as lutas das camadas populares (CARVALHO, 2001).

Revbea, São Paulo, V. 15, № 3: 274-296, 2020. 
fácil acesso através da internet, o educador na educação popular é responsável pela filtragem do que chegará aos agropecuaristas para início das discussões. Como destaca Carvalho (2001, p. 49), "a afinidade da Educação Ambiental Popular com o marco da nova extensão rural remete à vocação de uma Educação Ambiental que pretende promover mudanças nos níveis mais profundos das relações socioambientais". Assim, com esse conjunto composto por informações confiáveis e conhecimento tradicional prévio vê-se possível um despertar para a conscientização ambiental nesse setor econômico.

\section{Principais políticas e planos que abrangem Educação Ambiental relacionados à mudança do clima e agropecuária}

Após anos de lutas por conscientização, atualmente as questões ambientais estão posicionadas em um lugar de maior visibilidade, sendo incluídas em diversas políticas nacionais e estreitadas em projetos locais. Assim, observa-se que existem estratégias na busca do desenvolvimento da sociedade de forma sustentável e para enfrentar a crise da degradação dos recursos naturais e da poluição ambiental. De maneira genérica, alguns exemplos de estratégias que podem ser utilizadas são políticas públicas, a EA, o planejamento energético, o controle de poluição e de dejetos, entre outras (GODOY; WIZNIEWSKY; FERREIRA, 2013).

No entanto, apesar dos anos que transcorreram para se consolidar como instrumento de gestão ambiental, atualmente a Educação Ambiental vê-se enfraquecida como um caminho de transformação social. Os recentes Decretos Federais no 9.672, de 2 de janeiro de 2019 e no 9.665, de 2 de janeiro de 2019 reestruturaram os Ministérios do Meio Ambiente e Ministério da Educação, respectivamente, extinguindo setores da Educação Ambiental desses ministérios que constituíam o Órgão Gestor da Política Nacional de Educação Ambiental (PNEA). Nesses moldes, Educação Ambiental foi restringida à atuação de uma Secretaria de Ecoturismo do Ministério do Meio Ambiente.

Ainda que o debate sobre muitas questões ambientais encontre-se estagnado, ou até mesmo em retrocesso, o país possui a legislação ambiental que embasa e guia as ações a serem tomadas. A legislação existe para regulamentar as atividades, partindo do pressuposto que a garantia de qualidade de vida e a preservação do meio ambiente são patrimônio público e, por isso, devem ser asseguradas.

Em competência federal, o Brasil apresenta principalmente a base legal descrita a seguir que faz alusão à educação associada ao meio ambiente ou EA:

- Constituição da República Federativa do Brasil (1988): em seu Inciso VI do parágrafo $1^{\circ}$ do Art. $225^{\circ}$ do capítulo voltado ao meio ambiente consta a importância de se "Promover a Educação Ambiental em todos 
os níveis de ensino e a conscientização pública para a preservação do meio ambiente".

- Política Nacional do Meio Ambiente (PNMA): a Lei Federal no 6.938 de 1981 esclarece como um de seus princípios a "Educação Ambiental a todos os níveis de ensino, inclusive a educação da comunidade, objetivando capacitá-la para participação ativa na defesa do meio ambiente".

- Política Nacional de Educação Ambiental (PNEA): instituída pela Lei Federal o 9.795, de 27 de abril de 1999 e regulamentada pelo decreto no 4.281, de 2002. Conhecida como Lei de Educação Ambiental, em sua seção III Da Educação Ambiental Não-Formal Art. 13. Entendem-se por Educação Ambiental não-formal as ações e práticas educativas voltadas à sensibilização da coletividade sobre as questões ambientais e à sua organização e participação na defesa da qualidade do meio ambiente. Parágrafo único. O Poder Público, em níveis federal, estadual e municipal, incentivará VI - a sensibilização ambiental dos agricultores.

A seguir alguns instrumentos nacionais que tratam especificamente da Educação Ambiental no contexto da mudança do clima:

- Política Nacional sobre Mudança do Clima (PNMC): instituída pela Lei Federal no 12.187 de 2009, que estabelece seus princípios, objetivos, diretrizes e instrumentos. De acordo com o Art $5^{\circ}$ dessa Lei, "a promoção da disseminação de informações, a educação, a capacitação e a conscientização pública sobre mudança do clima" estão entre as diretrizes da PNMC. Além disso, inclui "as medidas de divulgação, educação e conscientização" como instrumentos da PNMC no Art $6^{\circ}$.

- Plano Nacional sobre Mudança do Clima: apresentado oficialmente em cerimônia no Palácio do Planalto no dia 1ํ de dezembro de 2008 e visa a incentivar o desenvolvimento e aprimoramento de ações de mitigação no Brasil, colaborando com o esforço mundial de redução das emissões de gases de efeito estufa, bem como objetiva a criação de condições internas para lidar com os impactos da mudança do clima. Possui quatro eixos, estando a Educação representada em "educação, capacitação e comunicação". Nesta seção são destacadas "Ações de Educação Ambiental", sendo relatado que "nas escolas, as mudanças climáticas são abordadas pela Conferência Nacional Infantojuvenil pelo Meio Ambiente (CNIJMA), Vamos cuidar do Brasil, criada no âmbito da Conferência Nacional do Meio Ambiente, em 2003". Segundo esse plano, as conferências devem trabalhar com temáticas socioambientais no currículo a partir da educação integral, visando também torná-las ambientes para 0 engajamento das comunidades em diálogos de saberes e a vivência de democracia participativa. 
- Fundo Nacional sobre Mudança do Clima: criado pela Lei Federal no 12.114/09 e regulamentado pelo Decreto oㅜ 7.343 , de 26 de outubro de 2010, o Fundo Clima possui como objetivo assegurar recursos para apoio a projetos ou estudos, e financiamento de empreendimentos que visem à mitigação da mudança do clima e à adaptação à mudança do clima e aos seus efeitos. Dentre as atividades que podem ser atendidas por esse fundo estão as ligadas à "educação, capacitação, treinamento e mobilização na área de mudanças climáticas”.

Com base nessa legislação, Sorrentino et al. (2005, p.287) destaca que a EA pode consistir em ações políticas através da educação para a cidadania, colaborando para a construção de uma sociedade preocupada com o meio em que vive. Diante disso, considera-se que a PNEA apresenta um roteiro genérico para o desenvolvimento da prática da EA, consistindo em uma ferramenta básica, mas útil.

Por outro lado, apesar do arcabouço teórico e legal que a EA brasileira está embasada, Tamaio (2013) salienta que as diretrizes elaboradas e que devem ser implementadas pela política pública de EA não possuem um direcionamento específico para o enfrentamento da mudança do clima. Logo, o autor destaca a urgente necessidade de formulação de políticas públicas que sejam adaptadas a demanda e realidade do país.

Nesse sentido, sabe-se que as soluções esperadas por meio da EA somente são alcançadas com a elaboração de programas com seriedade, com a determinação de objetivos, metas e ações claras para atender o que se deseja (SANTOS, 2000). Segundo as recomendações de Wood e Wood (1987) no estudo "How to plan a conservation education program", para o desenvolvimento e bom andamento de um programa de EA sugere-se orientarse por etapas baseadas em: a) identificação do público; b) avaliação da realidade ambiental; c) identificação da mensagem; d) seleção de uma estratégica educativa e e) avaliação.

Tendo-se claras essas ideias, nota-se o caráter transversal da EA, corroborando sobre o que destaca Tavares (2014, p.83):

A Educação Ambiental surge com a responsabilidade de provocar uma transformação da linearidade, disciplinaridade, dicotomia inerente das nossas práticas educativas e tem como desafio o rompimento com essa lógica. As discussões em âmbito nacional e internacional direcionam para que apenas por uma prática interdisciplinar, em que o meio ambiente seja entendido como um todo sem fronteiras, perpassando transversalmente todas as áreas do conhecimento, é que o objetivo da Educação Ambiental poderá ser vislumbrado. 


\section{Desafios da educação para a mudança do clima no setor agropecuário}

Por ser um assunto que atualmente está na mídia, a maioria das pessoas já ouviu falar sobre mudança do clima, mas não compreendem como colaboram para esse problema e como suas consequências afetarão suas vidas. Além disso, a população com pouca orientação e estudo desconhece como pode agir para reduzir a sua contribuição para a emissão de GEE, o que segundo Tamaio (2013) provoca uma "inércia da sociedade frente à questão das mudanças climáticas". Assim, embora atualmente seja um assunto que pode ser considerado difundido na sociedade em geral, ainda há barreiras para a implantação e desenvolvimento de ações de EA ligadas à mudança do clima. Nesse âmbito, os relatórios globais da IALEI apontaram como os principais desafios os seguintes pontos:

- A educação como uma ferramenta essencial para a manutenção e/ou incremento do poderio econômico. No atual cenário de acirrada competitividade econômica global, há em muitos países a tendência de se privilegiar como foco de aprendizagem as disciplinas científicas em detrimento de outras preocupações, dentre as quais os temas ambientais;

- A não conformidade entre o que as políticas públicas determinam e a prática concreta no ambiente escolar;

- A não formação dos docentes diante de temas tão complexos quanto a mudança do clima. Todos os dez países que participaram da avaliação afirmaram que lhes faltam professores suficientemente preparados para que a questão ambiental possa ser trabalhada com a devida competência que o tema exige;

- Trabalhar a EA em uma perspectiva estritamente científica e comportamentalista. Essa abordagem, bastante presente no ensino escolar, deixa de reconhecer e valorizar o enorme potencial de questões que se enquadram mais no âmbito da cidadania e da ética a partir de uma perspectiva crítica.

Nesse sentido, como apontam Gaudiano e Cartea (2009), a principal barreira para uma verdadeira mudança, no que diz respeito à complexa natureza estrutural do problema da mudança do clima, é que

existem obstáculos de ordem moral, sócio-política, cultural, sócio cognitiva e psicossocial que condicionam a representação social por parte da população, e dificultam a adoção de mudanças significativas nos estilos de vida, individuais e coletivos, relacionados com as atividades humanas que desequilibram o clima. 
Segundo Jacobi (2003, p. 189), as questões ambientais estão envolvidas por um grupo, havendo os mais variados sistemas de conhecimentos, capacitação de profissionais e de centros acadêmicos e pela sociedade como um todo, onde têm-se uma interdisciplinaridade entre os envolvidos. Assim, a EA deve ser proposta a partir da interdisciplinaridade e da transdisciplinaridade entre os contextos sociais, ambientais, econômicos e escolares, formando uma perspectiva integradora entre estes fatores.

Logo, o esforço requerido também está em como levar informação sobre o meio ambiente e problemas como a mudança do clima para os proprietários de terra, agricultores, pecuaristas e aqueles que de alguma forma trabalham com o solo e produção de alimentos no meio rural. Esse caminho começa com a percepção da realidade da qual fazem parte, sobre como a participação de todo e qualquer trabalhador faz e deve fazer a diferença. Isso não exclui de maneira nenhuma os saberes historicamente presentes nessas comunidades. Muito pelo contrário, atividades que são praticadas há muitos anos pelas comunidades estão enraizadas por se sustentarem ao longo do tempo, de outra maneira, não poderiam serem exercidas por muitos anos.

Como posiciona-se Jacobi (2003, p. 190):

a produção do conhecimento deve necessariamente contemplar as inter-relações do meio natural com o social, incluindo a análise dos determinantes do processo, o papel dos diversos atores envolvidos e as formas de organização social que aumentam o poder das ações alternativas de um novo desenvolvimento, numa perspectiva que priorize novo perfil de desenvolvimento, com ênfase na sustentabilidade socioambiental.

Como defende Tamaio (2013, p. 49), a "EA tem papel importante ao apresentar as causas e consequências, mas a solução tem de estar vinculada ao envolvimento de todos os cidadãos". Nesse sentido, o autor salienta que a EA é capaz de "inserir as pessoas no cerne da questão", o que potencializa "o senso de urgência e a necessidade de transformação imediata" para o enfrentamento da mudança do clima. Neste sentido é que a EA visa colaborar e sustentar um novo pensamento, promovendo a conscientização dos pequenos, médios e grandes produtores rurais, resgatando suas características e a cidadania por meio da participação nos processos de decisão das ações a serem tomadas para a conservação do meio ambiente. Esta inclusão se faz pela sua participação efetiva na melhoria da qualidade de vida ambiental e da sociedade, alinhando-se o social e o ambiental.

Em um momento em que a busca por máximo lucro a qualquer custo é incentivada, inclusive no campo agropecuário, torna-se ainda mais importante 
que os vínculos entre as pessoas e a natureza sejam fortalecidos no campo. Nesse setor, é da natureza que são obtidas as matérias-primas, é através do solo que as plantas crescem e se nutrem. A agricultura e a pecuária precisam ser desenvolvidos de maneira sustentável não somente para buscar reduzir a emissão de gases de efeito estufa, mas para que a própria atividade possa ser exercida sequencialmente.

No entanto, podemos notar a existência de diferentes atores no meio rural e acredita-se que as estratégias com o foco especificamente em reduzir a emissão de gases de efeito estufa seriam mais efetivas quando guiadas pelas demandas dos produtores ou proprietários das terras. Para o grande produtor rural ou grande proprietário de terras, sem muito contato com o campo, que possui máquinas e funcionários que realizam o trabalho, embora haja preocupação com a terra e a água, o mais importante é o lucro, estando a preocupação ambiental em segundo ou terceiro plano. $O$ posicionamento histórico desse grupo de proprietário e/ou empresários deixa claro que para este tipo de indivíduo seria mais eficaz focar em educação formal, onde sejam destacados o que a legislação exige, as condicionantes relacionadas às questões ambientais que os bancos impõem para o crédito rural, assim como as imposições que empresas estrangeiras estabelecem quando da exportação em relação às condições ambientais de produção, armazenamento e transporte dos produtos. Neste sentido, se esses sujeitos não possuem interesse em alterar a forma com que exercem suas atividades para reduzir as emissões de GEE, uma forma mais efetiva seria que as orientação sejam norteadas pelo que esses indivíduos estariam dispostos a atender, mesmo que para isso tenha que se associar exigências ambientais ligadas ao mercado.

Sobre o pequeno produtor, que em sua maioria possui uma propriedade familiar, estando realmente ligado ao trabalho no campo, pensa-se que podem ser adotadas ações de educação formal e não formal através da Educação Ambiental popular para instrumentá-los e orientá-los. Por estarem mais conectados à terra, vê-se que o despertar com a preocupação ambiental teria vantagens na melhoria da qualidade do ambiente de trabalho, além de refletir na manutenção da qualidade do solo, das águas e das florestas por um período maior em função de uma maior sustentabilidade de sua atividade.

Embora essas direções sejam baseadas na realidade da maioria dos produtores, são generalistas, e logo, devem ser ponderadas pelas demandas pessoais ou das associações de produtores. Vale ser destacado que isso tudo é associado a dependência ou não que o indivíduo tem da terra. $\mathrm{O}$ grande proprietário tem a opção de quando o ambiente for esgotado e degradado mudar de atividade ou investir em outro lugar. Já o pequeno produtor, raramente tem essa opção, o que muitas vezes acaba no êxodo rural e na marginalização urbana.

Somado a isso, um dos principais desafios em que se depara ao atrelar esses três campos, mudança do clima, economia e agropecuária, é nos posi- 
cionarmos diante de produtores rurais que mesmo buscando o lucro máximo, estão inseridos em ambientes sensíveis, onde o lucro máximo é limitado somente à sobrevivência da família. Para Seidel e Foleto (2008), os produtores familiares que se encontram nessas áreas ambientalmente sensíveis necessitam produzir para garantir a subsistência de suas famílias e, geralmente nessa busca pelo aumento da produtividade, causam problemas ao solo e à água.

Diante dessas realidades, é possível entender que a percepção do problema ambiental não é homogênea, por isso a necessidade de uma conscientização global quanto à importância da natureza, respeitando as diversas culturas (LEFF, 1998). Corroborando essa ideia, Fernandes et al. (2019) defende que a percepção ambiental pode ser entendida como a tomada de consciência do ambiente pelo homem, isto é, o homem passaria a compreender o ambiente do qual faz parte, e assim passaria a interagir com esse ambiente em uma perspectiva responsável. Assim, cada indivíduo e sociedade percebem e reagem diferentemente sobre o ambiente onde vivem. Estas respostas são decorrentes dos resultados das percepções construídas de forma coletiva ou individual, pelos processos cognitivos e pelas expectativas e julgamentos que cada sujeito pratica.

O entendimento de que os problemas ambientais não devem ser colocados em um patamar superior aos problemas econômicos pessoais nos permite defender o posicionamento de que as comunidades, não somente as ligadas à agropecuária, têm o direito de saber como suas vidas poderão ser afetadas pelas consequências da mudança do clima. As informações científicas produzidas por regiões e para todo o país, publicadas pelo IPCC e por demais instituições deveriam ser disponibilizadas às populações que estão sendo ou serão afetadas pelas mudanças do clima em linguagem que thes seja acessível. Como defende Barbanti Júnior (2017), a agropecuária não dará, sozinha, respostas a mudança do clima, mas o conhecimento é essencial para que os piores cenários climáticos não se concretizem.

$\mathrm{Na}$ EA para a mudança do clima, os educadores ambientais, formais e não formais, de dentro ou de fora das associações rurais e das comunidades de produtores em geral possuiriam o papel de atualizar o conhecimento sobre como a ciência do solo, agricultura, pecuária e as práticas realizadas diariamente afetam e podem ser afetados pela mudança do clima. De acordo com a World Wide Fund for Nature - WWF e o coletivo Ecoar (WWF; ECOAR, 2009) os educadores e educadoras ambientais brasileiros têm habilidade e conhecimento para assumir ambos papeis. Como os ciclos da natureza são elementos cruciais na história dos povos e na medida em que estes ciclos vêm sendo alterados pelo aquecimento global, gerando insegurança e instabilidade às comunidades, a atuação dos educadores ambientais nesta área precisa ser redimensionada à luz da nova realidade, não descartando o conhecimento tecnológico e a troca e diálogo de saberes. É vista a necessidade urgente de alterações no estilo de vida da maior parte da população e de seus hábitos de consumo, de adequações do modelo econômico de produção, de transporte, 
das práticas de descarte de resíduos, e todos esses fatores exigem ações de grande abrangência. As redes sociais e a mídia podem disseminar informações e propiciar conquistas no avanço do pensamento ambientalmente mais equilibrado (WWF; ECOAR, 2009).

Tamaio (2013) aponta que a EA como ação mobilizatória, crítica e transformadora é capaz de contribuir para enfrentar os cenários projetados para o futuro. Portanto, é por meio da EA sobre a mudança do clima que se espera gerar pensamentos que contribuam para um aumento da consciência das pessoas envolvidas com a agricultura e pecuária. Através da reflexão e do entendimento dos problemas e de como a sociedade precisa se posicionar diante da mudança do clima, que os produtores rurais e as pessoas envolvidas com o uso do solo devem ser incentivados a realizarem suas tarefas de maneira que causem menos impacto ao meio ambiente. Vale destacar que, além de atividades que reduzam as emissões de gases de efeito estufa, a conscientização das pessoas pode aumentar o sequestro de carbono no solo, o que reflete na mitigação das emissões, visto que assim ocorre o processo de remoção. Essas ações de mitigação e adequação para a mudança do clima são enquadradas na perspectiva da Educação Ambiental reativa.

\section{Considerações finais}

Ao longo do estudo, diversas discussões sobre mudança do clima, agropecuária, conservação do solo e Educação Ambiental foram expostas. $O$ melhor entendimento sobre a real contribuição da agropecuária para a mudança climática evidenciou a importância das ações de educação nesse setor. Além disso, diante das conexões que esses assuntos possuem, através da revisão bibliográfica e da exploração de ideias de importantes pesquisadores foi possível observar e entender alguns caminhos pelos quais a Educação Ambiental no setor agropecuário poderia ajudar a enfrentar a principal causa da mudança do clima, o aumento da concentração de gases de efeito estufa na atmosfera de origem das atividades antrópicas, dentre elas a agropecuária. Conforme exposto, no Brasil as atividades que fazem uso do solo são aquelas que mais contribuem para essas emissões. Portanto, toda e qualquer atividade voltada a esse setor que atenda os princípios da Educação Ambiental é de extrema importância para controlar e reduzir os problemas ambientais advindos desse setor.

O levantamento de informações mostrou que há alternativas para a redução das emissões de gases de efeito estufa e para tornar a agricultura e a pecuária mais sustentáveis. No entanto, de nada adianta as pesquisas científicas apontarem o que pode ser feito e não serem tomadas medidas para que essas informações cheguem a quem realiza na prática as atividades no campo, tanto para os pequenos, médios e grandes produtores rurais.

Portanto, somente seriam possíveis avanços na agropecuária, relativamente às questões ambientais, se o processo de formação dos 
profissionais da área for fortemente embasado nos princípios da Educação Ambiental, abordando a metodologias da educação formal e não-formal, incluindo a educação popular. Felizmente, com a maior notoriedade das questões ambientais, muitos cursos de engenharia agronômica, agrícola, medicina veterinária e zootecnia incluem em seus currículos disciplinas que abordam assuntos como a preservação ambiental e produção mais sustentável. Além disso, algumas instituições de assistência técnica organizam seminários e palestras que incluem temas sobre a preservação do meio ambiente. Por outro lado, muito conhecimento, dicas e sugestões que são compartilhados entre os produtores também são legítimos à Educação Ambiental. Neste contexto, com o objetivo específico de reduzir as emissões de gases de efeito estufa, acredita-se que as estratégias precisam focar nas demandas do produtor ou do proprietário da terra. Ou seja, se eles percebem a importância da melhor qualidade de trabalho e do ambiente ou somente estão interessados em cumprir as exigências legais e de crédito bancário para produzir e comercializar seus produtos, visto que para aqueles que não têm o meio ambiente entre suas prioridades, estar em conformidade com a legislação é considerado um avanço.

\section{Referências}

AZEVEDO, L.V. et al. Educação Ambiental e legislação: reflexões sobre participação e efetividade. Revista Brasileira de Educação Ambiental, v. 12, n. 2, p. 284-295, 2017.

BARBANTI JÚNIOR, O. Mudanças climáticas, agricultura e segurança alimentar: um caminho para o desastre. Friedrich Ebert Stiftung, n. 34, 2017.

BARROS, L. A.; LIHTNOV, D. D. Reflexões sobre a educação rural e do campo: as leis, diretrizes e bases do ensino do campo no Brasil. Geographia Meridionalis, v. 2, n. 1, p. 20-37, 2016.

BRASIL. Lei no 12.114, de 09 de dezembro de 2009. Brasília, DF. Presidência da República. Disponível em: <http://www.planalto.gov.br/ccivil 03/ Ato20072010/2009/Lei/L12114.htm>. Acesso em: 28 mai. 2018.

BRASIL. Lei no 12.187, de 29 de dezembro de 2009. Brasília, DF. Presidência da República. Disponível em: <http://www.planalto.gov.br/ccivil 03/ ato20072010/2009/lei//12187.htm >. Acesso em 13 mai. 2018.

BRASIL. Lei no 6.938, de 31 de agosto de 1981. Brasília, DF. Presidência da República. Disponível em: <http://www.planalto.gov.br/ccivil 03/leis/l6938.htm>. Acesso em 11 mai. 2018.

BRASIL. Lei no 9.795, de 27 de abril de 1999. Brasília, DF. Presidência da República. Disponível em: <http://www.planalto.gov.br/ccivil 03/leis/19795.htm>. Acesso em: 11 mai. 2018. 
BRASIL. Constituição da República Federativa do Brasil. Brasília, DF: Senado Federal: Centro Gráfico, 1988. Disponível em: $<$ http://www.planalto.gov.br/ccivil 03/constituicao/constituicao.htm>. Acesso em: 11 mai. 2018.

BRASIL. Decreto no 9.672, de 2 de janeiro de 2019. Brasília, DF. Presidência da República. Disponível em: <http://www.planalto.gov.br/ccivil 03/ ato20192022/2019/decreto/D9672.htm>. Acesso em: 06 ago. 2019.

BRASIL. Decreto no 9.665, de 2 de janeiro de 2019. Brasília, DF. Presidência da República. Disponível em: <http://www.planalto.gov.br/ccivil 03/ ato20192022/2019/decreto/D9665.htm>. Acesso em: 06 ago. 2019.

CARLOS, S.M. Percepção e adaptação às mudanças climáticas de agricultores da bacia hidrográfica do rio das contas, Bahia. 2016. Dissertação (Mestrado em Economia Aplicada) - Departamento de Economia Rural - Universidade Federal de Viçosa, Viçosa, 2016.

CARSON, R. Silent Spring. New York: Houghton and Mifflin, 1994. 368 p.

CARVALHO, I.C.M. Discutindo a Educação Ambiental a partir do diagnóstico em quatro ecossistemas no Brasil. Educação e Pesquisa, v. 31, n. 2, p. 301 313, 2005.

CARVALHO, I.C.M. Qual Educação Ambiental? Elementos para um debate sobre Educação Ambiental e extensão rural. Agroecologia e Desenvolvimento Rural Sustentável, v. 2, n. 2, 2001.

FERNANDES, R. S. et al. Uso da Percepção Ambiental como Instrumento de Gestão em Aplicações Ligadas às Áreas Educacional, Social e Ambiental. Disponível em: $<$ http://www.redeceas.esalq.usp.br/noticias/Percepcao Ambiental.pdf $>$. Acesso em: 15 mar. 2019.

FONSECA, J.J.S. Metodologia da pesquisa científica. Fortaleza: UEC, 2002.

GAUDIANO, E.G.; CARTEA, P.M. Educación, comunicación y cambio climático: resistencias para la acción social responsable. Revista Trayectorias, v. 11, n. 29, p. 6-38, 2009.

GODOY, C.M.T.; WIZNIEWSKY, J.G.; FERREIRA, A.G. Como os agricultores familiares percebem a Educação Ambiental? Revista Eletrônica do Curso de Direito da UFSM, p. 572-585, 2013.

INTERGOVERNMENTAL PANEL ON CLIMATE CHANGE. Mitigation of Climate Change. Working Group III Contribution to the Fifth Assessment Report of the Intergovernmental Panel on Climate Change. EDENHOFER, O.R. et al. (eds). Cambridge: Cambridge University Press, 2014. 1435 p. 
INTERNATIONAL ALLIANCE OF LEADING EDUCATION INSTITUTES. Climate Change and Sustainable Development: The Response from Education: a crossnational report from International Alliance of Leading Education Institutes. Denmark: IALEI, 2009. 355 p.

JACOBI, P. Educação Ambiental, Cidadania e Sustentabilidade. Cadernos de Pesquisa, n. 118, p. 189-205, 2003.

JACOBI, P.R. et al. Mudanças climáticas globais: a resposta da educação. Revista Brasileira de Educação, v. 16, n. 46, 2011.

LEFF, E. Saber Ambiental, sustentabilidad, racionalidad, complejidad, poder. México: Siglo XXI/UNAM/PNUMA, 1998. 416 p.

MADDISON, D. The perception of and adaptation to climate change in Africa. The World Bankm Development Research Group, Sustainable Rural and Urban Development Team, 2007. 51 p.

MATTA, C. R. Sustentabilidade ou sustentabilidades? a conceituação do termo pelos pesquisadores em Educação Ambiental. 2013. Dissertação (Mestrado em Educação Ambiental) - Instituto de Educação - Universidade Federal de Rio Grande, Rio Grande, 2013.

MINISTÉRIO DO MEIO AMBIENTE. Plano Nacional sobre Mudança do Clima. Disponível em: <http://www.mma.gov.br/clima/politica-nacional-sobremudanca-do-clima/plano-nacional-sobre-mudanca-do-clima>. Acesso em: 17 mai. 2019.

PELLEGRINO, G.Q.; ASSAD, E.D.; MARIN, F.R. Mudanças climáticas globais e a agricultura no Brasil. Revista Multiciência, n. 8, p. 139-162, 2007.

PIDGEON. N.; FISCHHOFF, B. The role of social and decision sciences in communicating uncertain climate risks. Nature Climate Change, v. 1, n. 1, p. 35-41, 2011.

PLASTINO, C. A. Freud e Winnicoott: a psicanálise e a percepção da natureza - da dominação à interação. In: CARVALHO, I. C. M.; GRÜN, M.; TRAJBER, R. Pensar o Ambiente: bases filosóficas para a Educação Ambiental. Brasília: Ministério da Educação, Secretaria de Educação Continuada, Alfabetização e Diversidade, UNESCO, p. 139-156, 2006.

REIGOTA, M. O que é Educação Ambiental. 2.ed. São Paulo: Brasiliense, 2009. 107p.

SAHEB, D.; RODRIGUES, D. G. A contribuição da complexidade de Morin para as pesquisas em Educação Ambiental. Revista Eletrônica do Mestrado de Educação Ambiental, edição XVI Encontro Paranaense de Educação Ambiental, p. 191-207, 2017. 
SANTOS, A. S. R. Educação Ambiental e o Poder Público. Programa Ambiental a Última Arca de Noé. Salvador: Revista Jurídica, 2000.

SARTORI, S.; LATRÔNICO, F.; CAMPOS, L. M. S. Sustentabilidade e Desenvolvimento Sustentável: uma taxonomia no campo da literatura. Ambiente \& Sociedade, v. 17, n. 1, p. 1-22, 2014.

SATO, M. Educação Ambiental. São Carlos: Rima, 2003. 66 p.

SECRETARIA DE AGRICULTURA FAMILIAR E COOPERATIVISMO. Apresentação de novas medidas do Plano Safra a agricultores do MS. Disponível em: <http://www.mda.gov.br/sitemda/noticias/apresenta\%C3\%A7\%C3\%A3o-denovas-medidas-do-plano-safra-agricultores-do-ms >. Acesso em: 17 mar. 2019.

SEIDEL, V.S.; FOLETO, E.M. Propostas de ações em Educação Ambiental visando a efetivação da legislação ambiental em áreas rurais no município de Santa Maria. Geografia, v. 17, n. 1, 2008.

SISTEMA DE ESTIMATIVA DE EMISSÃO DE GASES DO EFEITO ESTUFA Emissões Totais 2017. Disponível em: <http://seeg.eco.br/>. Acesso em 01 nov. 2017.

SORRENTINO, M. et al. Educação Ambiental como Política Pública. Educação e Pesquisa, v. 31, n. 2, p. 285-299, 2005.

TAMAIO, I. Educação Ambiental e mudanças climáticas: diálogo necessário num mundo em transição. Brasília: Ministério do Meio Ambiente, 2013. 104p.

TAVARES, G.S. O que pensam os professores sobre a criação de uma disciplina de Educação Ambiental? Revista Brasileira de Educação Ambiental, v. 8, n. 1, p. 83-90, 2014.

UNITED NATIONS. Sustainable Development Goals. Disponível em: $<$ https://www.un.org/sustainabledevelopment/>. Acesso em: 15 set. 2018.

WOOD, D.S.; WOOD, D.W. How to plan a conservation education program. Washington: Fish and Wildlife Service, 1987. 49 p.

WORLD WIDE FUND FOR NATURE; COLETIVO ECOAR. Educação Ambiental em tempos de Mudanças Climáticas. Brasília: WWF, 2009. 4.p. 